\title{
Repensando o acesso ao cuidado na Estratégia Saúde da Família'
}

\section{Rethinking the access to healthcare in the Family Health}

\section{Strategy}

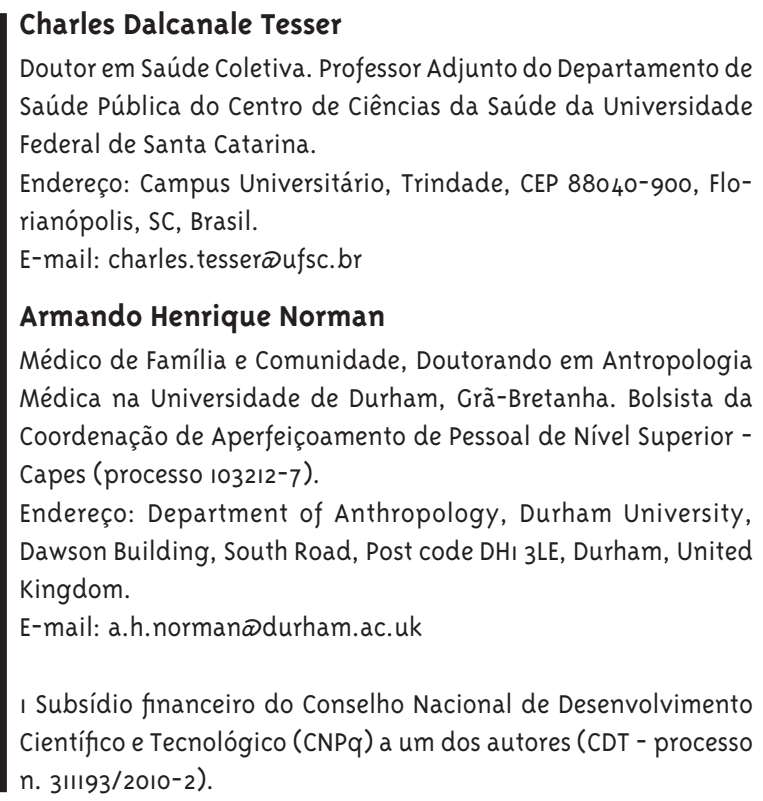

\section{Resumo}

Este artigo apresenta hipóteses interpretativas sobre a ausência de regulamentação institucional do acesso - caracterizado por certo desvio e/ou subvalorização do mesmo - na atenção primária à saúde (APS) brasileira, especialmente na Estratégia Saúde da Família (ESF), no seu aspecto de prover acesso rápido ao cuidado clínico longitudinal aos adoecidos e ou demandantes. As hipóteses para esse problema foram contextualizadas em dois eixos: nas normativas do SUS e nas discussões presentes na área da saúde coletiva. No primeiro eixo apresenta-se uma discussão envolvendo a influência histórico-cultural norte-americana na saúde pública brasileira, a visão focalizada de APS como "cesta básica" de serviços, a priorização da promoção/prevenção nas diretrizes institucionais, o acolhimento (única diretriz estimuladora do acesso fácil na ESF/APS) e o dimensionamento da proporção usuários/equipes da ESF, o que fundamenta a defesa da expansão dessas equipes e o seu redimensionamento. No segundo eixo faz-se uma discussão crítica envolvendo o relativo isolamento brasileiro da experiência dos países desenvolvidos com APS forte, a influência da crítica das relações entre a biomedicina e o capitalismo, a ênfase na promoção e prevenção como objetivos prioritários de trabalho nas equipes da ESF/APS, o distanciamento do meio acadêmico das realidades dos serviços da ESF e a estratificação social que fomenta o uso subsidiado do sistema privado pelas camadas médias e elites brasileiras. Por fim, se propõe a revalorização do acesso fácil ao cuidado com longitudinalidade como fundamental para concretizar as quatro lógicas que devem convergir nas práticas da APS/ESF: ético-política, antropológica, epidemiológica e de determinação social da saúde-doença.

Palavras-chave: Atenção Primária à Saúde; ESF; Acesso aos Serviços de Saúde; Acolhimento; Políticas Públicas de Saúde. 


\section{Abstract}

This article presents interpretative hypothesis about the absence of institutional rules for healthcare access to Primary Health Care (PHC) in Brazil, specifically in Family Health Strategy (FHS). Access now is characterized by deviation and/or undervaluation in its operational aspect of providing rapid access to longitudinal clinical care. The hypothesis for this problem has been contextualised along two main axes: SUS institutional norms and the internal debate within the Collective Health field. In the first axis we discuss the North-American influence on Brazilian public health and the understanding of PHC as a "basic package" of healthcare services; the priority given to health promotion in the institutional health policies, as well as the Embracement (the only policy to stimulate the easy access in PHC/FHS) and the sizing of users/FHS team ratio. All that gives support for expanding and resizing the users/FHS ratio. The second axis, discuss Brazil's relative isolation from the experience of developed countries with strong PHC; the critique of the relationship between biomedicine and capitalism; the emphasis on health promotion and disease prevention as the priority working objectives in PHC/FHS; the distance kept by the academic environment of the reality of FHS services; Brazilian social stratification, which fosters the use of subsidized private health systems by elites and middle classes. Finally, we argue that easy access to longitudinal healthcare should be regarded as fundamental for achieving the four dimensions which must converge into the PHC/FHS action: the ethical-political, anthropological and epidemiological dimensions and the social determinants on health and disease.

Keywords: Primary Health Care; Family Health Strategy; Health Services Accessibility; Embracement; Health Public Policy.

\section{Introdução}

Embora o acesso universal seja princípio do Sistema Único de Saúde (SUS) e histórica bandeira da reforma sanitária, o movimento institucional, o debate e as lutas pela garantia do acesso ao cuidado no SUS parecem ter esfriado ao longo dos anos posteriores à sua legalização. Não obstante esse tema ter sido abordado pelo Programa Saúde da Família (PSF), posteriormente renomeado Estratégia Saúde da Família (ESF), como eixo reestruturador e expansor da atenção primária à saúde (APS) brasileira, a discussão institucional sobre o acesso foi ativada apenas tardiamente através da diretriz do acolhimento (Brasil, 2004).

É consenso que a expansão da APS via ESF ampliou o acesso ao cuidado (Sousa, 2008; Silva e col., 2013; Teixeira e Solla, 2005), mas há também relativa concordância sobre ele ainda ser precário (Azevedo e Costa, 2010), mesmo onde a ESF já está estabelecida. Recente revisão englobando artigos dos últimos 20 anos sobre o acolhimento na APS/ESF concluiu que a ausência de articulação em redes integradas, o excesso de demanda, o modelo biomédico hegemônico, a ausência de capacitação, bem como de espaços democráticos e reflexivos para reorganizar o processo de trabalho em saúde, têm colocado em questão, de modo cada vez mais incisivo, a potencialidade dessa diretriz (Mitre e col., 2012).

Em buscas de artigos científicos que mensurassem o acesso aos serviços apenas na dimensão restrita de tempo de espera por quem procura ser atendido no mesmo dia ou agendar um atendimento na APS/ESF brasileira, com vários descritores incluindo acesso e acolhimento, não se encontrou em dezenas de resumos inicialmente selecionados um único que dimensionasse descritivamente esse tempo, no país, num Estado, município, distrito ou grupo de unidades de saúde. Várias avaliações da APS/ESF têm enfoques sistêmicos e abrangentes, mas não têm avaliado com proximidade a situação do acesso dos que procuram o cuidado; ou o abordam apenas superficial e tangencialmente, como em Silva e colaboradores (2013), Mitre e colaboradores (2012), Azevedo e Costa (2010), Sousa e Merchán-Hamann (2009), Sousa (2008), Conill (2002). Parece que não se sabe, e não houve interesse em investigar, a dis- 
tribuição do tempo de espera para atendimento por um profissional da equipe responsável pelo cuidado ao usuário na APS/ESF.

Um exemplo ilustra algo desse universo: em 2009, estudo envolvendo os 47 centros de saúde (CS) de Florianópolis-SC (99 equipes da ESF cobrindo $80 \%$ da população) descreveu as formas de acesso ao cuidado clínico e a média de tempo de espera estimado em semanas para se obter um atendimento: em $84,5 \%$ dos CS o tempo de espera era de quatro semanas ou mais, com pouco agendamento para enfermeiros e variados esquemas de avaliação para atendimentos no mesmo dia ("urgências" ou "acolhimento"), para os quais havia algumas vagas reservadas nas agendas dos médicos. Em 76.5\% dos centros de saúde havia reserva de vagas para grupos prioritários - idosos, gestantes, crianças até 2 anos, diabéticos, hipertensos etc. (Luz e Tesser, 2009). 0 acesso parece precário quando se tem que esperar várias semanas para atendimento não urgente na APS/ESF.

Como resultado geral, após mais de duas décadas de SUS, as equipes da APS/ESF não oferecem disseminadamente acesso fácil a seus usuários nem dispõem de tecnologias organizacionais consolidadas para tal (além da diretriz genérica do acolhimento); muito pouco se sabe a respeito e não se observam acirradas disputas institucionais e políticas ou pesquisas com esse foco. Isso justifica esforços para uma melhor compreensão da questão e indica a necessidade de repensá-la.

Este artigo objetiva apresentar hipóteses interpretativas e reflexões sobre o acesso na APS/ESF, no sentido específico do acesso ao cuidado em caso de adoecimento ou procura espontânea (agendado ou no mesmo dia) nos serviços já instalados. Do ponto de vista metodológico, foram realizadas interpretações histórico-políticas associadas a discussões teóricas, escrutinadas pela experiência empírica na organização e prática assistencial em vários serviços da ESF/APS, durante cerca de década e meia de cada autor (pequena parte como docentes). 0 trabalho está organizado em dois eixos temáticos com interseções e interinfluências mútuas, nos quais elementos ou fatores de várias naturezas (históricos, políticos, teórico-conceituais, contextuais) são associados. $\mathrm{O}$ primeiro enfoca as normativas insti- tucionais da APS/ESF e o segundo, as discussões na saúde coletiva sobre a atuação dos profissionais que atuam nessa área. Inicialmente, em cada eixo, caracterizou-se o que foi considerado como um "desvio" e certa subvalorização do problema do acesso, questões relevantes para além do precário acesso comumente existente.

A seguir são apresentadas hipóteses interpretativas sobre alguns fatores envolvidos na manutenção desse "desvio" e na dificuldade de superá-lo, sem ordem de importância entre eles. Apesar do foco na ESF, entende-se que a discussão é válida, com adaptações, para o restante da APS brasileira.

Quanto ao primeiro eixo, foi desenvolvida uma discussão abordando a influência histórico-cultural norte-americana na saúde pública brasileira, a visão focalizada de APS como "cesta básica” de serviços, a priorização da promoção/prevenção nas diretrizes institucionais e o acolhimento (única diretriz estimuladora do acesso fácil na ESF/APS). Argumenta-se, ao final, sobre a importância da expansão das equipes da ESF e seu redimensionamento para viabilização do acesso. No segundo eixo faz-se uma discussão crítica envolvendo o relativo isolamento brasileiro da experiência dos países desenvolvidos com APS forte, a influência da crítica das relações entre a biomedicina e o capitalismo, a ênfase na determinação social da saúde-doença como objeto de trabalho na APS/ESF, o distanciamento do meio acadêmico das realidades dos serviços e a estratificação social que fomenta o uso subsidiado do sistema privado pelas camadas médias e elites brasileiras (inclusive sanitárias).

É difícil avaliar o peso que os fatores tematizados teriam num cômputo geral dos dilemas do acesso ao cuidado clínico qualificado na APS/ESF, dada sua complexidade. Eles certamente são limitados e insuficientes para uma compreensão abrangente da problemática e, por isso, devem ser considerados e relativizados em um universo amplo de forças políticas, institucionais e históricas. Apesar disso, trata-se de temática estratégica a ser considerada, sobretudo por que sobre "nós" (da saúde coletiva e da APS/ESF - profissionais, docentes/pesquisadores e gestores) recai significativa responsabilidade no sentido de contribuir para a revalorização do acesso fácil ao cuidado com longitudinalidade como eixo 
fundamental na concretização social das quatro dimensões que devem estar presentes e sinérgicas nas práticas da APS/ESF: ético-política, antropológica, epidemiológica e de determinação social da saúde-doença, cuja síntese constitui o último tópico deste trabalho.

\section{0 acesso ao cuidado nas normativas da APS/ESF}

Ao se comparar o acesso com a longitudinalidade, quanto aos desdobramentos organizativos desses atributos fundamentais da APS (Starfield, 2002; Giovanella e col., 2008), observa-se que a segunda foi contemplada com uma clara regra administrativa que a induz ou facilita: a adscrição territorial de clientela às equipes como requisito para a implantação de uma equipe de saúde da família (SF). O acesso ficou restrito ao princípio genérico da universalidade, sem regulamentações específicas. 0 único mecanismo indireto a ele relacionado foi (e ainda é) a recomendação da média de 3 mil e o limite de 4 mil pessoas adscritas a cada equipe de SF (Brasil, 2006, 2011), frequentemente desrespeitado.

O acesso envolve vários aspectos (geográfico, econômico, sociocultural, funcional), mas a garantia do acesso ao cuidado àqueles que procuram os serviços já existentes da APS/ESF, foco desta reflexão, ficou restrita à diretriz do acolhimento e às linhas genéricas dos textos oficiais, que, via de regra, enfatizaram outras ações na APS, com ressalvas do tipo "sem prejuízo das atividades assistenciais". Por exemplo, em texto institucional de 200o, época da transformação do Programa Saúde da Família em estratégia brasileira para organização da APS, dentre as responsabilidades de uma equipe de SF há uma única que se relaciona ao acesso ao cuidado, das oito mencionadas: "prestar assistência integral, respondendo de forma contínua e racionalizada à demanda, buscando contatos com indivíduos sadios ou doentes, visando promover a saúde por meio da educação sanitária” (SPS, 200o, p. 318-319).

Na Política Nacional de Atenção Básica (Brasil, 2006) persiste relativa desproporção discursiva entre a garantia do acesso e outras atividades. Apesar de ressaltar a atenção básica como "porta de entrada preferencial" e a "integração de ações programáticas e demanda espontânea” (p. 11) como seus princípios gerais, na caracterização do processo de trabalho, das dez características listadas apenas duas relacionam-se com o acesso e a atenção à demanda, em seus finais de frase: "programação e implementação das atividades com a priorização de solução dos problemas de saúde mais frequentes, considerando a responsabilidade da assistência resolutiva à demanda espontânea”; "implementação das diretrizes da Política Nacional de Humanização, incluindo o acolhimento" (p. 18-19 - grifos dos autores) e uma terceira que se refere estritamente a urgências médicas. Torna-se desnecessária uma análise de discurso para perceber que a garantia do acesso não é item prioritário. 0 fato de o acolhimento e a atenção à demanda aparecerem em fins de frase e começarem com "considerando" e "incluindo" sugere fortemente que os tópicos principais são os que vieram antes desses verbos, assim como as outras oito características descritas. Nos princípios gerais específicos da saúde da família e nos seus processos de trabalho nenhum item trata do acesso facilitado e longitudinal na APS/ESF. A menção à "demanda espontânea" volta a aparecer nas atribuições comuns dos profissionais da saúde da família e nas atribuições específicas apenas dos médicos.

Somente na nova Política Nacional de Atenção Básica (Portaria n⿳0 2.488, de 21 de outubro de 2011) há um discurso mais favorável à questão do acesso. Dos cinco fundamentos e diretrizes elencados, novamente em primeiro lugar aparece a ênfase explícita na promoção a saúde - impactar a situação, os condicionantes e determinantes da saúde das coletividades que constituem aquele território. O segundo item é voltado para o acesso ao cuidado, com uma significação elaborada ausente no texto de 2006; o terceiro item aborda a longitudinalidade; o quarto a interdisciplinaridade e o quinto a participação social e política dos usuários. Apesar dessa maior valorização do acesso, não há nenhum parâmetro ou normatização que signifique mecanismo "concreto" de indução, garantia ou estabelecimento de regras claras sobre o acesso ao cuidado.

Uma possibilidade de compreensão parcial desse vazio normativo sobre o acesso pode vir da consideração de forças históricas e culturais envolvidas na constituição dos centros de saúde brasileiros e da 
própria saúde pública nacional, anteriores ao SUS (e que influenciaram também a saúde coletiva). A rede básica brasileira foi influenciada pela tradição norte-americana em que os centros de saúde, desde sua origem, eram vistos como serviços de saúde pública e de controle de doenças voltados aos pobres, cuja função dirigia-se à prevenção, às vacinações, à educação sanitária e ao tratamento de doenças endêmicas e/ou de relevância coletiva, com pouca responsabilidade pelo cuidado clínico aos indivíduos (Campos, 2007; Rosen, 1979). Complementarmente, na (re)construção dos sistemas nacionais de saúde nas últimas décadas, os países de baixa e média renda foram fortemente influenciados pelas diretrizes do Relatório para o Desenvolvimento Mundial do Banco Mundial de 1993 (World Development Report). As reformas propostas nesse documento incluíam estratégias de descentralização, participação, pacotes assistenciais básicos, financiamento misto (cost-sharing) ou privatização, além de melhora no sistema de informação (Atkinson, 2002). Historicamente formatado pela ideologia do Banco Mundial - de uma atenção primária seletiva com pacotes assistenciais básicos (Giovanella e col., 2008) - o Programa Saúde da Família nasceu com prioridade para prevenção de doenças, promoção da saúde, ações programáticas (Schraiber, 1990) e grupos de risco (Tesser e col., 2010), embora nunca se tenha negado ou menosprezado explicitamente a assistência ao sofrimento.

Todavia, o tema do acesso aparece oficialmente por outra via, em 2004, com a edição da Política Nacional de Humanização (PNH) (Brasil, 2004). É chamativo que a sua tematização e facilitação institucional na APS tenham começado por iniciativas locais municipais e, após algum êxito dessas experiências - uma registrada (Franco e col., 1999) -, tenha sido embutida na proposta do acolhimento, dentro da PNH.

0 acolhimento propõe ampliar o acesso e concretizar o objetivo da APS/ESF de ser a principal "porta de entrada" do SUS, além de promover uma melhoria qualitativa nas relações dos profissionais com os usuários (Mitre e col., 2012). A elaboração a seu respeito carrega desde o início uma dupla significação: além do aspecto organizativo de facilitar o acesso, envolve o resgate ético da melhoria da relação profissional-usuário (Tesser e col., 2010). Nesse segundo sentido, o acolhimento tem um caráter transversal, perpassando todas as atividades do SUS, com uma natureza abrangente e uma proposta calcada no interesse pelo outro, numa postura ética de cuidado e numa abertura humana, empática e respeitosa ao usuário.

0 acolhimento induz a reformulação da tradição burocrática e rígida dos serviços de saúde em todas as suas esferas. Isso se reflete na questão do acesso aos serviços na APS, com vistas a flexibilizar e ampliar a clínica, facilitando o cuidado do usuário dentro das equipes da ESF. $\mathrm{O}$ atendimento integral desafia os profissionais, pois amplifica as incertezas. O contato não programado passa a ocorrer (ou deveria ocorrer) diretamente com a equipe de saúde e requer uma prática profissional com importante grau de comunicação, interpretação, negociação e responsabilidades compartilhadas, estimulando o vínculo, acalmando as ansiedades e buscando resoluções contextualizadas para os problemas (Tesser e col., 2010). Isso tende a atenuar as mazelas do centramento do primeiro contato na consulta médica e sua comum transformação em "pronto atendimento", com pouca resolutividade em casos crônicos, tendente ao padrão "queixa-conduta" e medicalizante (Gonçalves, 1994; Cunha, 2005). Tal indução e qualificação do acesso fomentaram discussões e experimentações sobre essa necessidade fundamental da APS/ESF, facilitando a interdisciplinaridade, a escuta, a potencialização e a ampliação da clínica de todos os profissionais da equipe (Franco e col., 1999; Campos, 2003).

Por outro lado, a diretriz do acolhimento tem gerado também uma tensão nos processos de trabalho e na formação dos profissionais, pois não acabou com a dicotomia artificial e a falsa oposição entre "demanda programada" e "demanda espontânea". Historicamente, a priorização de ações programadas e programáticas foi fortalecida pelo pensamento preventivista (ou, no desejo de muitos sanitaristas, promocionista, conforme adiante discutido), que segue sendo a diretriz para a organização dos serviços, induzindo priorização nos processos de trabalho de grupos de risco (diabéticos, hipertensos, gestantes, citopatológicos, crianças), com consequência nas práticas da saúde da família (Teixeira e Solla, 
2005; Conill, 2002). Em muitos serviços, ou talvez na maioria deles, pouco espaço nas agendas é destinado para atenção às queixas/sofrimentos dos usuários, muitos dos quais são assistidos em prontos atendimentos ou emergências hospitalares, sobrecarregando estas últimas (devido ao excesso ali de pessoas que deveriam ser atendidas na ESF) e descaracterizando aqueles (SF) como serviços de APS (Oliveira e col., 2009).

Além disso, o acolhimento talvez esteja produzindo efeitos ambíguos e/ou "colaterais", à medida que se efetivou em muitos lugares a renomeação do acesso pelo acolhimento, borrando, de certa forma, o acesso em si mesmo como direito essencial e característica básica da APS/ESF. A diretriz apela para uma ética que, embora fundamental, pode parecer desvinculada do caráter estritamente necessário do acesso para a efetivação da APS/ESF enquanto estruturante do SUS, sua universalidade e equidade.

Em parte isso pode ter sido facilitado pela dupla significação do termo acima mencionada. Muitas vezes, serviços pendem unilateralmente para um dos lados dessa dupla significação, com efeitos indesejáveis paradoxais observáveis na prática quando, por exemplo, se recusa cuidado "delicadamente", sacrificando o acesso com postura acolhedora. Por outro lado, como vem sendo tratado em vários serviços, o acolhimento acaba sendo simplificado como uma triagem de urgências (por exemplo, o "Protocolo de Manchester", adotado - ou importado - por algumas secretarias de saúde municipais), para salvaguardar uma agenda priorizada com serviços e programas institucionalizados. Aquilo que não se encaixa nas "prioridades programáticas" ou simplesmente não está agendado é avaliado por técnicos de enfermagem ou enfermeiras e encaixado conforme a preferência do profissional ou o grau de urgência da situação. Como a flexibilidade das agendas é pequena, torna-se comum os usuários serem referidos para os prontos atendimentos ou emergências.

Outra situação indesejável e corriqueira ocorre quando se operacionaliza o acolhimento viabilizando acesso a um cuidado pontual, sacrificando-se a longitudinalidade e, com isso, a qualidade: quem acolhe não é profissional da equipe de SF responsável. Por exemplo, Luz e Tesser (2009) mostraram que em $80 \%$ dos 47 centros de saúde de Florianópolis o atendimento à demanda espontânea do dia (não agendados) não era organizado por equipe, ou seja, não era adscrito por área de abrangência. Em uma parte não determinada desses serviços podia haver alguma negociação com os profissionais da equipe responsável na tentativa de resolução do problema. Em 16\% dos centros de saúde haviam profissionais desvinculados da ESF realizando um pronto atendimento na APS. Pouco se sabe sobre o restante do país a esse respeito e as pesquisas não têm enfocado a longitudinalidade, aspecto crucial da qualidade do cuidado e do acesso (Starfield, 2002).

Por outro lado, o acolhimento não deve ser reduzido, como frequentemente ocorre, a uma atividade-fim, que é dar resposta às necessidades sentidas pelos usuários. Assim, a avaliação de riscos e vulnerabilidades (percepção de necessidades clínico-biológicas, epidemiológicas e psicossociais) e a eleição de prioridades na produção de rápida resposta ao usuário talvez não devessem ser confundidas com algo diferente de acesso ao cuidado de boa qualidade nem renomeadas como acolhimento, visto que tais atividades são inerentes à responsabilidade de provisão de cuidado da APS/ESF. A comum troca de terminologia (acesso por acolhimento) pode estar gerando confusão, tanto para a educação profissional como para as práticas dos serviços.

$\mathrm{O}$ fato da equipe de SF assumir a responsabilidade de atender seus usuários nas suas demandas, ouvindo-os e negociando soluções para seus problemas da melhor e mais rápida forma possível, deve ser caracterizado como praxe na APS/ESF na sua função essencial de cuidar longitudinalmente. Esse ethos não pressupõe uma nomenclatura nova, ainda que esta nomeie uma iniciativa que visou corrigir uma distorção historicamente construída. Tal questionamento abre a possibilidade de que seja desejável e estratégico pensar para um futuro não remoto a "emancipação" do acesso do acolhimento. Este último reteria em si seus significados de priorização da qualificação das interações de cuidado em geral, necessária em todas as práticas profissionais. O acolhimento ficaria, então, depurado da ambiguidade de sua dupla significação e preservaria seu significado ético e político de garantia de direitos e de humanização dos serviços de saúde, ainda um desafio para o SUS. Isso poderia reacender, uma vez 
que destacada e revalorizada em si mesma, a luta pelo direito universal de acesso ao cuidado longitudinal rápido e de qualidade, a ser incorporado como obrigação expressa das equipes de SF, traduzida em diretiva nacional específica, a ser detalhada e pactuada localmente, permitindo avaliação, fiscalização e aperfeiçoamento nos serviços, pelos usuários e pela gestão. Tal regulamentação facilitaria a responsabilização e o protagonismo dos gestores locais, da equipe de SF e também da comunidade organizada, em negociação recíproca. Para isso, operacionalmente, as agendas de médicos e enfermeiros devem ser pelo menos igualmente divididas entre o cuidado aos demandantes e o conjunto das outras atividades - cuidado agendado, ações programáticas etc.

Se a abertura da ESF/APS para um acesso facilitado exige um novo pensar e agir nos serviços, o mesmo se aplica ao Ministério da Saúde. Cabe ao órgão revisitar os parâmetros da ESF para torná-la mais acessível ao cidadão, por meio de estímulos e incentivos, para que mais profissionais migrem para esse campo de atuação, nele fixando-se; e para a construção de mecanismos asseguradores do acesso. Pouco adianta ter como bandeira facilitar o atendimento qualificado e longitudinal dos usuários se não se rediscutir a proporcionalidade entre equipe e população adscrita.

Por exemplo, em 1961, White e colaboradores (1961) descreveram o perfil populacional de busca por serviços na APS britânica. Fundamentado em parte nos registros dos médicos generalistas (General Pratictioners) britânicos, o estudo documentou que em uma população de 1.000 adultos, durante o período de um mês, 750 pessoas relataram alguma queixa em saúde. Dessas, 250 consultaram seu médico, nove foram hospitalizadas, cinco foram referidas para outros médicos e uma foi encaminhada a um hospital universitário. Com base nisso, o sistema de saúde inglês reorientou a estruturação de serviços e a cobertura populacional. Uma equipe da APS inglesa se responsabiliza por 1.500 a 2.00o pessoas, o que aporta uma demanda a esses profissionais em torno de 500 pessoas/mês. 0 estudo foi refeito em 2001 por Green e colaboradores (2001) e a nova estimativa foi similar à primeira. Outros países apresentam proporções semelhantes usuários/médicos na APS: Dinamarca, 1.6oo; Espanha, 2.50o; Itália, 1.03o; Portugal, 1.50o; e Holanda, 2.350 (Giovanella e col., 2008).

No Brasil, os critérios que serviram de base para a determinação do volume de usuários adscritos às equipes da ESF são pouco claros, e refletem sua construção histórica mais focada em pacotes básicos (ações programáticas para grupos de risco), como mencionado anteriormente. Porém, esse volume tem importantes implicações para a prática no que se refere ao acesso e à carga de trabalho da equipe da SF, influenciando a satisfação do usuário e dos profissionais de saúde. Ao se tentar realizar um "bom" acolhimento viabilizando acesso, comumente, gera-se nas equipes angústia, carga extenuante de trabalho e estresse emocional. São necessários profissionais em número suficiente para possibilitar condições de trabalho que permitam acesso e atendimento das pessoas na longitudinalidade, e a gestão local deve fornecer suporte institucional para a sua valorização e permitir a continuidade do cuidado no contexto das iniquidades sociais brasileiras, o que implica em abertura de espaços democráticos rotineiros de gestão do trabalho, como reuniões semanais das equipes de SF (Tesser e col., 2010).

Mas, se quisermos ter um padrão de assistência com efetividade clínica e sanitária (ou seja, na direção de um modelo de APS abrangente), adequado à realidade nacional e que forneça acesso ao cuidado, um passo fundamental é diminuir o volume de usuários adscritos por equipe de SF, e continuar expandindo as equipes da ESF para cobrir pelo menos 80\% da população. A experiência de outros países e a brasileira, a precária condição social da maioria da nossa população (geradora de adoecimento e demandas adicionais aos serviços), a extensão territorial do país (e suas características geográficas e demográficas), bem como o trabalho em equipe apontam para a necessidade de redução dos usuários para cerca de 2.500 pessoas, em média, por equipe de SF, o que deve variar com o contexto social.

Além disso, cada vez mais novas responsabilidades ("programas", "políticas", "linhas de cuidado", "funções”) voltadas para doenças, grupos, problemas ou situações específicas são criadas ou descentralizadas para a APS/ESF. Os usuários associados a essas responsabilidades irão merecer cuidados, o que também suscita a revisão da população adscrita às equipes de SF, de modo que se conciliem e integrem 
ações curadoras, reabilitadoras, preventivas e de promoção. Portanto, é necessário que existam incentivos e regras claras para que os gestores municipais possam efetivar tais modificações e serem cobrados pelas equipes de SF e pela sociedade organizada.

\section{O tema do acesso fácil ao cuidado} na saúde coletiva

Se nas normativas da APS/ESF há certo desvio, desregulamentação e ou subvalorização da questão do acesso ao cuidado, na saúde coletiva essa discussão não tem sido muito diferente, tanto do ponto de vista teórico como operacional. Na revisão sobre acolhimento de Mitre e colaboradores (2012), englobando 20 anos, somente 26 artigos foram incluídos e o acesso aparece apenas como um dos muitos temas relacionados. Sua operacionalização é abordada de forma relativamente sucinta e genérica (por poucos artigos, ilustrando o desvio do tema), ficando destacada a potencialidade e os limites do acolhimento para a melhoria do acesso.

Em discussão sobre modelos assistenciais, o acesso é considerado por Teixeira e Solla (2005, p. 464) em termos genéricos, de "extensão de cobertura da atenção básica”, através da ampliação numérica das equipes de SF. Seu enfoque passa ao largo do acesso e parece induzir, com efeito, uma valorização positiva da sua situação na APS/ESF, dada sua escassez pregressa, subvalorizando (por omissão) a constatação de que o mesmo é muito insuficiente e pouco qualificado. Os autores concluem o texto sem menção ao acesso, aproximando-se do tema apenas quando comentam que "tudo o que se vem fazendo, [...] na medida em que amplia a oferta de serviços básicos" significa "a racionalização do modelo hegemônico", que "apenas arranha” sua superfície e evidencia o quão distante ainda se está de um sistema "de serviços de saúde que opere segundo a lógica da intervenção sobre determinantes, riscos e danos, nesta ordem de prioridades, e não o contrário, como continua a acontecer”. Há uma perspectiva que privilegia a mudança de paradigma, na "direção da sonhada 'reversão' do modelo de atenção à saúde, de modo a que venha privilegiar as ações de promoção e vigilância, redefinindo as ações assistenciais"
(Teixeira e Solla, 2005, p. 471-472).

Discutindo modelos de atenção alternativos ao chamado modelo médico hegemônico, Paim (2008) lista nove propostas e apresenta sinteticamente seis delas, uma das quais o acolhimento. Apesar de o autor mencionar que a maioria "tenta conciliar o atendimento à demanda espontânea e às necessidades na perspectiva da integralidade da atenção" (p.562), uma análise de seus conteúdos revela que tematizam mais saberes, tecnologias e práticas voltadas para a promoção da saúde (causas), a prevenção (riscos), o cuidado programado e o impacto em problemas tecnicamente detectados (danos epidemiologicamente orientados) do que para o acesso ao cuidado. Apenas o acolhimento está dirigido especificamente para o tema da atenção à demanda espontânea. Prioridade similar aparece em importante texto de referência para a clínica médica na APS: a base do "modelo clássico é a demanda espontânea. [...] é importante uma estruturação com base na demanda organizada [...] quando são apresentados desafios como centrar a atenção na pessoa saudável" (Duncan e col., 2004, p. 91).

Embora outros autores (Teixeira, 2003; Silva Júnior, 2006; Ayres, 2009) discutam propostas, conceitos e ideias relacionadas aos modelos de atenção e, assim, ao acesso - "em defesa da vida", ações programáticas, vigilância da saúde, distritos sanitários, cidades saudáveis, integralidade, vulnerabilidade, cuidado e humanização - as discussões e pesquisas voltadas ao fácil acesso ao cuidado não são volumosas e se concentraram em torno da diretriz do acolhimento e da ampliação/qualificação da clínica (Campos, 2003; Cecílio, 1994; Merhy e Onocko, 1997). Nota-se, assim, pouco acúmulo e certa subvalorização e/ou desvio desse problema. Várias razões podem ser aventadas para compreensão desse desvio do acesso na saúde coletiva, além das já mencionadas.

O distanciamento relativo da saúde coletiva e dos gestores do SUS das trajetórias de estruturação dos sistemas nacionais de saúde nos países de alta renda (como Inglaterra, Canadá, Espanha etc.) com APS forte pode estar envolvido nesse desvio. As experiências desses países são convergentes e não deixam dúvidas quanto à priorização do acesso ao cuidado como fundamental para efetividade da APS, 
como vimos acima no dimensionamento dos usuários adscritos: o acesso fácil com longitudinalidade necessita ser garantido, como passo essencial para a construção do direito ao cuidado adequado e sua coordenação pela APS, e também como redução das iniquidades em saúde (Starfield, 2002). Enquanto isso se desenrolava na Europa, no Brasil lutava-se contra a ditadura militar, para a redemocratização do país, para fazer a $8^{\text {a }}$ Conferência Nacional de Saúde, para legalizar o SUS, descentralizar e municipalizar os serviços. Vários anos mais foram necessários para induzir uma estruturação coerente da APS, o que só ocorreu a partir do meio da década de 1990, com o Programa Saúde da Família, depois ESF (Almeida e col., 200o).

Muitos líderes da reforma sanitária, nesse meio tempo, se transformaram em gestores do SUS ou políticos que submergiram no emaranhado da política brasileira, o que lhes consumiu a atenção e permitiu criar experiências inovadoras e pioneiras, as quais foram, e talvez ainda sejam, a mola propulsora do SUS. Mas isso parece ter sofrido de um isolamento relativo do debate internacional e dessas experiências estrangeiras de estruturação da APS.

Em outra vertente de compreensão do problema, pode-se considerar que, a partir de análises marxistas realizadas por pesquisadores e intelectuais da reforma sanitária e da saúde coletiva, a biomedicina foi fortemente associada à ordem social capitalista (Campos, 2005; Teixeira e Solla, 2005), em que o cuidado médico aparece mais como um mecanismo de reprodução da força de trabalho (Gonçalves, 1994; Donnangelo, 1975) voltado para os interesses político-econômicos do complexo médico-industrial e das classes dominantes. Tal olhar crítico convergiu com a pequena influência da biomedicina na melhora da morbimortalidade nos séculos XIX e XX em países europeus (Mckeown, 1976) e reforçou a ideia de determinação social do processo saúde-doença. Isso pode ter favorecido o desvio do problema do cuidado à demanda na direção da sobrevalorização da prevenção e promoção. Com isso, as características indesejáveis da clínica seriam atenuadas e/ou compensadas com uma valorização de atividades nas quais a epidemiologia, a promoção da saúde (Buss, 2003), a prevenção e o planejamento foram privilegiados. Desse modo, talvez, imaginava-se atingir determinantes sociais do processo saúde-doença, deixados incólumes pelo cuidado médico individual.

Por outro lado, segundo Fleck (2010), nos processos de socialização centrífuga do conhecimento especializado - dos núcleos de produção de saber científico (chamados pelo autor de círculos esotéricos) para especialistas e praticantes menos especializados (mais exotéricos) - há transformações nesse saber, com sua simplificação e dogmatização. Nessas transformações, a visão crítica da clínica pode ter se transformado em identificação do atendimento à pessoa que busca por cuidado com um “curativismo suspeito" vinculado ao modelo médico hegemônico. Isso permite compreender o fato comum de se observar tanto no ensino (academia, saúde coletiva) como nos serviços da APS/ESF um "comprometimento" com um "novo modelo" voltado à promoção/prevenção que mantém a subvalorização do cuidado à pessoa adoecida/em sofrimento.

Adicionalmente, o desvio do acesso pode ter sido facilitado pelo distanciamento situacional e existencial da maioria dos acadêmicos, pesquisadores e gestores brasileiros da experiência prática e dos processos de trabalho cotidiano na APS/ESF, o que gera uma situação que parece ocorrer em significativa medida: os que criam e propõem modelos, políticas, programas ou estratégias não as vivenciam, quer como usuários, quer como profissionais, afastando a "organicidade" dos processos de construção do SUS e da APS/ESF, na acepção gramsciana do termo (Frankenberg, 1988).

Além disso, o contexto de vida e os valores da elite sociocultural e política brasileira, inclusive a sanitária, são dominados culturalmente pelas especialidades médicas focais, visto que, nas suas práticas sociais, essas pessoas as usam rotineiramente. Tais grupos (acadêmicos, gestores, servidores públicos) e mesmo os profissionais de saúde do SUS têm acesso direto a médicos especialistas focais, por meio de seguros e convênios privados, significativamente subsidiados pelo Estado (vide, por exemplo, plano de saúde da Fiocruz: http://www.fiosaude.org.br/). Cerca de $20 \%$ dos gastos com planos de saúde brasileiros provêm de fontes públicas (Bahia, 2008).

Portanto, quando se fala de acesso ao cuidado entre gestores, profissionais e acadêmicos se está a falar do acesso dos "outros", os pobres, e isso faz toda 
a diferença. Em vez de um SUS universal que "nós" usamos através da ESF, o que se vem fazendo, em coerência com a criticada versão da "cesta básica”, parece mais uma APS para os "outros”, os pobres. Por outro lado, na necessidade e devido à precariedade do SUS, muitos usuários alimentam o mercado privado da média complexidade (especialidades e serviços privados de diagnose), que tem se expandido fortemente em paralelo ao sistema público.

Essas hipóteses interpretativas, associadas entre si e a outros fatores, sugerem que a APS brasileira vem sendo construída corroborando certo "apartheid" social aceito: aos pobres se reserva a precariedade do acesso a uma única equipe de SF, quando houver; enquanto à classe média e média alta (gestores, acadêmicos, políticos, profissionais do SUS) é reservado o acesso subsidiado com relativa livre escolha aos especialistas médicos no mercado privado.

Configura-se com isso um descompasso entre a norma jurídica, o discurso dos líderes, intelectuais/ acadêmicos e gestores do SUS, por um lado, e a sua prática social, por outro, que torna muito raro que um político, um gestor ou um pesquisador se trate rotineiramente na equipe de SF de seu bairro. Esse descompasso entre discurso e prática - provavelmente radicado na herança cultural colonialista e na abissal desigualdade social brasileira (Ribeiro, 1995) - reforçou a situação em que o SUS, no papel, é mais avançado que as representações, discursos e práticas de seus próprios líderes intelectuais e políticos, conseguindo se materializar apenas precariamente, em meio à resignação geral.

Esse contexto também facilita a compreensão da configuração de valores que prioriza mais a promoção da saúde e a ação epidemiologicamente orientada e menos o acesso e o exercício do cuidado clínico como nobres e complexas funções da APS/ESF. Os termos dessa comparação não são mutuamente excludentes ou necessariamente concorrentes; porém, a valorização diferencial os torna hierarquizados, reforçando como secundário o aspecto "curativo", envolvido essencialmente no acesso ao cuidado. Essa hierarquia de valores (primeiro a ação para transformação e impacto em determinantes coletivos e indicadores epidemiológicos e depois a atenção à demanda do usuário) pode desdobrar-se numa lógi- ca de trabalho em que o cuidado na APS/ESF é visto mais como um meio para atingir um fim e menos como um fim em si mesmo. Tal priorização e hierarquização, com efeito, podem significar uma inversão ética entre meios e fins, e parecem funcionar como um mecanismo de fuga da assunção completa e complexa da ética social de cura/cuidado das pessoas em seus sofrimentos, com suas dificuldades e limites, muitas vezes frustrantes para o sanitarista, já que de baixo impacto (ou nenhum impacto, para muitos problemas clínicos comuns) na morbimortalidade coletiva. Isso constitui o que poderíamos chamar de "paradoxo das ações nos serviços de saúde da APS/ ESF": ao mesmo tempo em que o cuidado deve ser prioridade, por mais abrangente, ampliado e de boa qualidade que seja, sabemos que ele não interfere de modo importante em determinantes sociais, em situações em que a concentração de renda, as iniquidades sociais, a precária infraestrutura sanitária e habitacional e a concentração de riqueza são muito grandes, como no Brasil. Nessas circunstâncias, estratégias promocionais e preventivas em âmbito microssocial (equipe de SF) têm relativamente pouco efeito nesses determinantes. Seu efeito é difuso e leve: contribui para melhoria da "consciência sanitária”, da organização popular para reivindicações e participação na gestão do SUS local etc.

O paradoxo das ações nos serviços da APS/ESF fica atenuado e pode ser mais facilmente superado na prática se for considerada uma distinção básica raramente ressaltada: a APS, na sua acepção ampla, abrange bem mais que os serviços de saúde de atenção primária. Aleixo (2002) destaca que já em Alma-Ata, além de ações educativas, preventivas e curativas, a APS envolve atendimento dos problemas de alimentação, abastecimento de água e saneamento básico em estreita cooperação com os setores sociais e econômicos, redistribuição dos recursos disponíveis em direção aos desassistidos, maior participação e controle pela sociedade. Essas funções ultrapassam os limites dos serviços de saúde da APS/ESF, embora possam ser problematizadas e abordadas neles, em dimensão individual, microssocial e comunitária. Ou seja, as ações promocionais e preventivas de amplitude populacional, na acepção de Rose (2010), estão na sua maior parte fora da alçada dos serviços de saúde da APS. Estudos 
sobre determinantes gerais e promoção da saúde têm corroborado essa perspectiva (Mckeown, 1976; Rose, 2010; Sícoli e Nascimento, 2003; Buss, 2003; Sousa, 2008).

Deve ser ressaltada a grande prioridade e necessidade dessas medidas populacionais de promoção da saúde no Brasil (Buss, 2003), mas isso não pode ser transposto simplesmente e/ou automaticamente para a organização e os objetivos do trabalho dos profissionais dos serviços da APS/ESF. Ao contrário, é razoável, defensável e importante considerar que o objetivo de promoção/prevenção, embora deva estar presente, não é nem deve ser a prioridade praticada (nem apenas retórica) das equipes da APS. Essas equipes, todavia, podem e devem trabalhar para criar e se envolver ativamente em projetos e ações nesse sentido. Mas seria uma inversão não efetiva de responsabilidades propor que funções de promoção/ prevenção fossem a prioridade desses profissionais, secundarizando o cuidado ao adoecimento.

Seria tentador e coerente almejar que uma consistente ação generalizada de politização e "empoderamento", realizada por dezenas de milhares de equipes de SF, poderia gerar uma mobilização político-social que alavancasse a reforma sanitária, a construção de um SUS na prática universal, equânime e integral, e assim uma transformação profunda setorial e social. Todavia, isso seria ingênuo e um tanto delirante, porque as condições e forças que sustentam a sociedade e a cultura globalizada capitalística/hierárquica/injusta hoje são as mesmas que obstruem o poder de difusão da crítica e da capacitação/transformação generalizada dos profissionais de saúde em se tornarem ativistas político-sociais ou pelo menos grandes educadores populares. Porém, mesmo que isso seja algo possível e digno de aposta (com o que os autores concordam), quem seriam os curadores das pessoas adoecidas a estarem disponíveis cotidianamente para atendê-las, senão esses mesmos profissionais da SF? E de que lugar social/existencial nasceria a legitimidade, o vínculo e a solidariedade para com os usuários nessa atividade promotora, senão do labor profissional, antropologicamente assentado na função de curadores desses profissionais? Embora estes últimos tenham se afastado histórica e politicamente desse papel social, transformando-o cultural e tecnologica- mente, ainda nele se baseiam. Isso reforça que o cuidado clínico continua sendo o cerne das funções dos profissionais dos serviços da APS/ESF, e os médicos e enfermeiros devem continuar dedicando a grande maioria do seu tempo - talvez, cerca de $70 \%$ a $80 \%$ ou mais dele - ao cuidado dos seus usuários adscritos, com acesso fácil aos adoecidos. Muita prevenção e promoção individual, familiar e comunitária pode e deve ocorrer nesse cuidado, para o que é crucial o acesso com longitudinalidade.

\section{A importância ético-política e antropológica do acesso ao cuidado}

"No alvorecer da humanidade, [...] a medicina em sua totalidade consistia de uma relação imediata entre a doença e o que a aliviava [...] ela foi estabelecida pelo indivíduo, de si e para si mesmo, antes de ter sido apanhada na rede social" (Foucault, 2003, p. 65). Na linha desse trecho de Foucault vale destacar que, por mais abrangentes que as ações dos serviços da APS/ESF sejam, seu núcleo básico inexorável de atuação é o cuidado ao sofrimento/adoecimento, que pode e deve ser associado a, mas não sobrepujado por funções gerais de saúde pública (vigilância, prevenção, promoção/educação). Como dissemos, a legitimidade da função curadora é o que potencializa o efeito educativo e "empoderador" e pode ampliar o espectro de ações em projetos de promoção da saúde.

É importante ressaltar que aquém e além do impacto sobre determinações sociais e indicadores epidemiológicos, a lógica ético-política e a lógica antropológica do cuidado devem se presentificar nas atividades das equipes da APS/ESF. A lógica ético-política vê o acesso das pessoas ao cuidado profissional como direito alicerçado na solidariedade social, na qual os recursos de cuidado devem ser ofertados de forma acessível, equânime, adequada, universal e com qualidade aos adoecidos (tudo indica que estes continuarão existindo em abundância) e à população adscrita aos profissionais, em geral sadia. Não se deve priorizar esta última em relação aos doentes, no cotidiano das equipes de SF, pois isso não se sustenta eticamente (doentes merecem tanto ou mais atenção que sadios, pois estão vulne- 
rabilizados) nem tecnologicamente (devido ao baixo poder preditivo dos recursos atuais voltados aos sadios individualmente); e também porque as ações preventivas/promotoras podem fluir sem obstrução do fluxo do cuidado clínico nos serviços, em paralelo ou associado a ele.

A lógica antropológica se fundamenta na constatação transcultural e histórica de que as sociedades desenvolveram especialização social (Berger e Luckmann, 1996) da função de cuidado/cura em curadores que concentram competências muito além do manejo autônomo familiar dos problemas de saúde. No SUS, os profissionais da ESF/APS são ou devem ser os curadores oficiais e universalmente acessíveis. Por outro lado, em uma terceira lógica (técnica e epidemiológica), estudos mostram o impacto sanitário da organização de uma APS forte estruturando e coordenando o cuidado às pessoas nos sistemas de saúde dos países com melhores condições sociossanitárias (Starfield, 2002). Essas três lógicas convergem para o imperativo da oferta de cuidado acessível/qualificado aos usuários adscritos. Por fim, uma lógica promotora deve enriquecer e complementar as anteriores, sem com elas competir discursiva ou operacionalmente.

O referencial epistemológico-tecnológico para a atenção à saúde mais institucionalizado no Ocidente é a biomedicina e as demais profissões da saúde. Os médicos destacam-se como agentes sociais nesse cuidado pela legitimidade no manejo do sofrimento (incluindo aí a "doença", notadamente a grave), além da concentração de poder social que envolve diagnose, legitimação de afastamentos do trabalho e manejo de tecnologias duras diagnósticas e terapêuticas (químico-cirúrgicas). No Brasil a formação técnica e cultural desses profissionais, tanto na graduação como pós-graduação, é dirigida na sua quase totalidade para outros tipos de trabalho que não na APS, e a maioria dos médicos da ESF não tem formação específica para atuar em equipe ali, nem lhe é exigida tal formação. Pelo contrário, têm formação em especialidades que não medicina de família e comunidade. Talvez o desvio do problema do acesso ao cuidado clínico tenha facilitado essa demora do país em dirigir a graduação e a residência médica para a formação de médicos de família e comunidade, como outros países em que quase metade dos médicos trabalha na atenção primária com formação específica. Profissionais qualificados atuando em equipes na APS são essenciais para construir acesso, resolubilidade, função filtro, coordenação e abordagens comunitárias e "empoderadoras".

Esse cenário complexo de ausência de construção organizada do acesso ao cuidado tem retardado o enfrentamento do problema da qualidade do trabalho médico na APS e a reforma da clínica doença-centrada. Esta última, por vezes, domina os serviços, dificultando a exploração da função cuidadora de outras profissões. Gera-se, assim, um processo em bola de neve contraproducente para a construção do acesso e de uma clínica ampliada, qualificada e centrada nas pessoas, que é virtuoso, todavia, para a manutenção da clínica doença-centrada. A visão crítica da clínica (mais ou menos simplificada) tende a "compensá-la" através da ênfase no promocionismo e preventismo, mas esses, no entanto, deixam-na intacta, ao desviarem-se dela. Mesmo que a priorização da promoção/prevenção tenha pouco ou nenhum efeito nas práticas (seja apenas retórica), ela produz resultado alimentando o desvio do problema do acesso fácil ao cuidado qualificado.

Essas reflexões indicam que o campo de implantação e legitimação da APS/ESF e do acesso ao cuidado longitudinal nela ainda está perigosamente desguarnecido, carente de uma massa crítica de líderes, técnicos, profissionais de saúde, acadêmicos, gestores e políticos envolvidos na construção de uma APS forte, acessível, estruturante do SUS e universal.

A construção do acesso, no que diz respeito ao rápido atendimento dos adoecidos adscritos e demandantes nos serviços da ESF/APS, como direito a ser garantido, é um tópico a ser reconsiderado na agenda da saúde coletiva e do SUS, merecedor de regulamentação geral que induza fortemente pactuação local e sua fiscalização por usuários e gestores. Além disso, há que reduzir o número de usuários por equipe e melhorar os processos de trabalho e agendas dos profissionais, construindo um equilíbrio entre cuidado à demanda com fácil acesso na longitudinalidade e outras ações agendadas e/ou programáticas (promoção, prevenção, coordenação do cuidado, educação permanente, matriciamentos etc.). 


\section{Colaboração dos autores}

Os autores participaram igualmente de todas as etapas da elaboração do artigo.

\section{Referências}

ALEIXO, J. L. M. A atenção primária à saúde e o Programa Saúde da Família: perspectivas para o início do terceiro milênio. Revista Mineira de Saúde Pública, Belo Horizonte, v. 1, n. 1, p.1-16, 2002.

ALMEIDA, C. et al. Health sector reform in Brazil: a case study of inequity. International Journal of Health Services, Baltimore, v. 30, n. 1, p. 129-162, 2000.

ATKINSON, S. Political cultures, health systems and health policy. Social Science \& Medicine, Boston, v. 55, n. 1, p. 113-124, 2002.

AYRES, J. R. C. M. Organização das ações de atenção à saúde: modelos e práticas. Saúde e Sociedade, São Paulo, v. 18, p. 11-23, 2009. Suplemento 2.

AZEVEDO, A. L. M.; COSTA, A. M. A estreita porta de entrada do Sistema Único de Saúde (SUS): uma avaliação do acesso na Estratégia de Saúde da Família. Interface: Comunicação, Saúde, Educação, Botucatu, v. 14, n. 35, p. 797-810, 2010.

BAHIA, L. As contradições entre o SUS universal e as transferências de recursos públicos para os planos e seguros privados de saúde. Ciência $\&$ Saúde Coletiva, Rio de Janeiro, v. 13, n. 5, p.13851397, 2008.

BERGER, P. L.; LUCKMANN, T. A construção social da realidade. 13. ed. Petrópolis: Vozes, 1996.

BRASIL. Ministério da Saúde. SecretariaExecutiva. Núcleo Técnico da Política Nacional de Humanização. HumanizaSUS: Política Nacional de Humanização: a humanização como eixo norteador das práticas de atenção e gestão em todas as instâncias do SUS. Brasília, DF, 2004.

BRASIL. Ministério da Saúde. Departamento de Atenção Básica. Política Nacional de Atenção Básica. Brasília, DF, 2006.
BRASIL. Ministério da Saúde. Portaria nº 2.488, de 21 de outubro de 2011. Aprova a Política Nacional de Atenção Básica, estabelecendo a revisão de diretrizes e normas para a organização da Atenção Básica, para a Estratégia Saúde da Família (ESF) e o Programa de Agentes Comunitários de Saúde (PACS). Diário Oficial da República Federativa do Brasil, Brasília, DF, 24 out. 2011. Seção 1, p. 48.

BUSS, P. M. Uma introdução ao conceito de promoção da saúde. In: CZERESNIA, D.; FREITAS, C. M. (Org.). Promoção da saúde: conceitos, reflexões, tendências. Rio de Janeiro: Fiocruz, 2003. p. 15-38.

CAMPOS, C. E. A. As origens da rede de serviços de atenção básica no Brasil: o Sistema Distrital de Administração Sanitária. História, Ciências, Saúde - Manguinhos, Rio de Janeiro, v. 14, n. 3, p. 877-906, 2007.

CAMPOS, G. W. S. Saúde Paidéia. São Paulo: Hucitec, 2003.

CAMPOS, G. W. S. Romance de formação de um sanitarista: um estudo de caso. In: LIMA, N. T.; GERCHMAN, S.; EDLER, F. C. (Org.). Saúde e democracia: história e perspectivas do SUS. Rio de Janeiro: Fiocruz, 2005. p. 121-150.

CECílIO, L. (Org.). Inventando a mudança na saúde. São Paulo: Hucitec, 1994.

CONILL, E. M. Políticas de atenção primária e reformas sanitárias: discutindo a avaliação a partir da análise do Programa Saúde da Família em Florianópolis, Santa Catarina, Brasil, 1994200o. Cadernos de Saúde Pública, Rio de Janeiro, v. 18, p. 191-202, 2002. Suplemento.

CUNHA, G. T. A construção da clínica ampliada na atenção básica. São Paulo: Hucitec, 2005.

DONNANGELO, M. C. Medicina e sociedade. São Paulo: Pioneira, 1975.

DUNCAN, B. B. et al. (Org.). Medicina ambulatorial: condutas em atenção primária baseadas em evidências. 3. ed. Porto Alegre: Artmed, 2004. FLECK, L. Gênese e desenvolvimento de um fato científico. Belo Horizonte: Fabrefactun, 2010. 
FOUCAULT, M. The birth of the clinic: an archaeology of medical perception. Abingdon: Routledge, 2003.

FRANCO, T. B.; BUENO, W. S.; MERHY, E. E. O acolhimento e os processos de trabalho em saúde: o caso de Betim, Minas Gerais, Brasil. Cadernos de Saúde Pública, Rio de Janeiro, v. 15, n. 2, p. 345353, 1999.

FRANKENBERG, R. Gramsci, culture, and medical anthropology: Kundry and Parsifal?: or rat's tail to sea serpent? Medical Anthropology Quarterly, Arlington, v. 2, n. 4, p. 324-337, 1988.

GIOVANELLA, L. et al. Políticas e sistema de saúde no Brasil. Rio de Janeiro: Fiocruz, 2008.

GONÇALVES, R. B. M. Tecnologia e organização social das práticas de saúde: características tecnológicas do processo de trabalho na rede estadual de centros de saúde de São Paulo. São Paulo: Hucitec; Rio de Janeiro: Abrasco, 1994.

GREEN, L. A. et al. The ecology of medical care revisited. New England Journal of Medicine, Waltham, v. 344, n. 26, p. 2021-2025, 2001.

LUZ, J.; TESSER, C. D. Implantação do processo de trabalho da Estratégia Saúde da Família em Florianópolis. 2009. Trabalho de Conclusão de Curso (Graduação em Medicina) - Departamento de Saúde Pública da Universidade Federal de Santa Catarina, Florianópolis, 2009.

McKEOWN, T. The role of medicine: dream, mirage or nemesis. London: The Nuffield Provincial Hospitals Trust, 1976. Disponível em: <http:// www.nuffieldtrust.org.uk/sites/files/nuffield/ publication/The_Role_of_Medicine.pdf $>$. Acesso em: 13 maio 2014 .

MERHY, E. E.; ONOCKO, R. (Org.). Agir em saúde: um desafio para o público. São Paulo: Hucitec, 1997.

MITRE, S. M.; ANDRADE, E. L. G.; COTTA, R. M. Avanços e desafios do acolhimento na operacionalização e qualificação do Sistema Único de Saúde na Atenção Primária: um resgate da produção bibliográfica do Brasil. Ciência \& Saúde Coletiva, Rio de Janeiro, v. 17, n. 8, p. 2071-2085, 2012.
OLIVEIRA, L. H.; MATTOS, R. A.; SOUZA, A. I. S. Cidadãos peregrinos: os "usuários" do SUS e os significados de sua demanda a prontos-socorros e hospitais no contexto de um processo de reorientação do modelo assistencial. Ciência \& Saúde Coletiva, Rio de Janeiro, v. 14, n. 5, p. 19291938, 2009.

PAIM, J. S. Modelos de atenção à saúde no Brasil. In: GIOVANELLA, L. et al. Políticas e sistema de saúde no Brasil. Rio de Janeiro: Fiocruz, 2008. p. 547-573.

RIBEIRO, D. O povo brasileiro: a formação e o sentido do Brasil. São Paulo: Companhia das Letras, 1995.

ROSE, G. Estratégias da medicina preventiva. Porto Alegre: Artmed, 2010.

ROSEN, G. Da polícia médica à medicina social: ensaios sobre a história da assistência médica. Rio de Janeiro: Graal, 1979.

SCHRAIBER, L. B. (Org.). Programação em saúde hoje. 2. ed. São Paulo: Hucitec, 1990.

SÍCOLI, J. L.; NASCIMENTO, P. R. Promoção de saúde: concepções, princípios e operacionalizações. Interface: Comunicação, Saúde, Educação, Botucatu, v. 7, n. 12, p. 101-122, 2003.

SILVA, L. A.; CHAVES, S. C. L.; CASOTTI, C. A. A produção científica brasileira sobre a estratégia saúde da família e a mudança no modelo de atenção. Ciência \& Saúde Coletiva, Rio de Janeiro, v. 18, n. 1, p. 221-232, 2013.

SILVA JÚNIOR, A. G. Modelos tecnoassistenciais em saúde: o debate no campo da saúde coletiva. 2. ed. São Paulo: Hucitec, 2006.

SOUSA, M. F. O Programa Saúde da Família no Brasil: análise do acesso à atenção básica. Revista Brasileira de Enfermagem, Brasília, DF, v. 61, n. 2, p. 153-158, 2008.

SOUSA, M. F.; MERCHAN-HAMANN, E. Saúde da Família no Brasil: estratégia de superação da desigualdade na saúde? Physis, Rio de Janeiro, v. 19, n. 3, p. 711-729, 2009. 
SPS - SECRETARIA DE POLITICAS DE SAUDE.

Departamento de Atenção Básica. Programa Saúde da Família. Revista de Saúde Pública, São

Paulo, v. 34, n. 3, p. 316-319, 2000.

STARFIELD, B. Atenção primária: equilíbrio entre necessidades de saúde, serviços e tecnologia.

Brasília, DF: Unesco: Ministério da Saúde, 2002.

TEIXEIRA, C. F. A mudança do modelo de atenção à saúde no SUS: desatando nós, criando laços.

Saúde em Debate, Rio de Janeiro, v. 27, n. 65, p.

257-277, 2003.
TEIXEIRA, C. F.; SOLLA, J. P. Modelo de atenção à saúde no SUS: trajetória do debate conceitual, situação atual, desafios e perspectivas. In: LIMA, N. T.; GERCHMAN, S.; EDLER, F. C. (Org.). Saúde e democracia: história e perspectivas do SUS. Rio de Janeiro: Fiocruz, 2005. p. 451-477.

TESSER, C. D.; POLI NETO, P.; CAMPOS, G. W. S. Acolhimento e (des)medicalização social: um desafio para as equipes de saúde da família. Ciência \& Saúde Coletiva, Rio de Janeiro, v. 15, p. 3615-3624, 2010. Suplemento 3.

WHITE, K. L.; WILLIANS, T. F.; GREENBERG, B. G. The ecology of medical care. New England Journal of Medicine, Waltham, v. 265, n. 18, p. 885-892, 1961. 